\title{
Introducción al número especial en psicología cultural y transcultural
}

\author{
Agustín Espinosa \\ Pontificia Universidad Católica del Perú
}

La presente edición de la Revista de Psicología busca promover un diálogo académico a partir de dos objetivos: el primero, proponer nuevos enfoques y alternativas de estudio de las influencias culturales en el comportamiento social, en la medida en que las teorías y herramientas existentes pueden resultar insuficientes y sesgadas para tal fin; el segundo objetivo es describir y analizar, de manera general, la interacción entre algunos procesos psicológicos básicos y la cultura propiamente dicha.

En este escenario, citamos a Hofstede (1991), quien define la cultura como una programación compartida en la mente de un grupo de individuos. Esta programación sirve como un punto de referencia para establecer diferencias entre distintos grupos a partir de los valores, creencias, actitudes y normas comportamentales que los mismos consideran relevantes (Lehman, Chiu \& Schaller, 2004). Hoy en día no se discute que la manifestación de diversos procesos psicológicos es comprendida con una mayor precisión desde una perspectiva cultural. El argumento a la base de la afirmación previa es que, en la medida en que como individuos nos desenvolvemos en un mundo social, tendemos a incorporar modelos, significados y prácticas culturales que influyen nuestros procesos psicológicos básicos (Fiske, Kitayama, Markus \& Nisbett, 1998). Esta incorporación de la cultura en términos 
evolucionistas debería maximizar nuestras posibilidades de adaptación al medio, pues nos brinda herramientas que nos facilitan la provisión de los recursos necesarios para alcanzar metas individuales y colectivas (Lehman, Chiu \& Schaller, 2004).

Los seis artículos aquí presentados son especialmente interesantes porque en su mayoría se centran en identificar los mejores caminos para comprender las relaciones entre algunos procesos psicológicos y la cultura, tomando como escenario el contexto latinoamericano. Esto es particularmente importante en la medida en que el estudio de la cultura desde la psicología social ha desarrollado nuevas propuestas conceptuales que no siempre han tomado en cuenta información de regiones como la nuestra.

Finalmente, es posible identificar en los artículos la posición que asumen los autores frente a las diversas teorías predominantes en los campos que les competen en sus análisis. Evidentemente, algunos resultan más críticos que otros con las mismas. En ese sentido, corresponde al lector juzgar los caminos teóricos y metodológicos que le parezcan más apropiados y que crea se ajusten mejor a una cabal comprensión de la realidad en la que se encuentra inmerso. Por tal motivo, esperamos que la lectura de este número especial despierte el interés en los temas relacionados con cultura y promueva el diálogo aludido al inicio de esta introducción. 